\title{
Acknowledgements and dedications
}

A number of people gave great support to the work that went into making this volume come to life as an edited collection. Colleagues at the African National Research Foundation (NRF) in association with the Human Sciences Research in South Africa and the Economic and Social Research Council (ESRC) in the UK were incredibly supportive through the challenging process of assembling a cross-national interdisciplinary programme of research on cities in Africa. In particular Jeremy Neathey and Julie McLaren were there at the ESRC when it mattered, persuading all partners to commit to funding the enterprise and believing in its value. Colleagues at the African Centre for Cities were extremely hospitable in hosting the workshop at which most of these chapters were presented in their early stages. Colleagues at COMPAS including Emma Newcombe, Mikal Ann Mast, Nathan Grassi, Julia Pointer, Karla-Maria Perez-Blanco and Vicky Kingsman all worked behind the scenes in Oxford to make international collaboration logistics a mobile reality as much as an emergent theoretical concern of the volume. Several people have read and contributed to the detail of the volume and particular thanks are due to AbdouMaliq Simone, Sue Parnell and two anonymous referees for reading and making constructive suggestions on the manuscript. Tom Dark has been incredibly supportive of the production of a book series that relates back to and beyond the ESRC Urban Transformations programme. The volume has also benefited significantly in its genesis in contributions and support from the PEAK Urban programme linking researchers in Bangalore, Cape Town, 
Medellín and Beijing. Perhaps more than any other single individual, Peter Grant has put an enormous amount of editorial work into this and other published work from the ESRC Urban Transformations programme that is too often both unseen and invisible.

We would like to dedicate the volume to the nameless numbers of scholars, researchers, activists and city makers in Africa and the UK that have died as result of the COVID-19 pandemic. We hope that this volume might make a small contribution to our thinking and their endeavours shaping better urban futures. 
Michael Keith and Andreza Aruska de Souza Santos - 9781526155351 Downloaded from manchesterhive.com at 04/26/2023 03: 00 :32PM 